\title{
Document-based service architecture for communication between health and wellness service providers and customers
}

\author{
Jaakko Lähteenmäki, Juha Leppänen, and Hannu Kaijanranta \\ VTT Technical Research Centre of Finland \\ Espoo, Finland
}

\begin{abstract}
Electronic communication between health and wellness service providers and customers is becoming more common. The paper introduces a new document-based service approach - PIR (Personal Information Repository) - supporting information to be sent between the provider and the customer. The advantage compared to existing solutions is that the service can be shared with several service providers, which allows the customer to use the same interface for many services. Furthermore, transmission of structured (HL7/CDA R2) documents is supported allowing semantic compatibility of exchanged health information. A user trial has been carried out for testing the solution. The results are encouraging and reflect considerable interest towards exchange of personal health and wellness information.
\end{abstract}

Index Terms-eHealth, health and wellness, security, service architecture.

\section{INTRODUCTION}

$\mathrm{E}$ LECTRONIC Health Records (EHRs) are increasingly used in public and private healthcare [1]. Major efforts are currently focused on linking local and regional EHRs into national and global architectures facilitating seamless availability of health information. In addition to linking healthcare organizations, the EHRs will provide an access to personal health and wellness information for the citizens. The citizen's requirements for information are considerably different from the organizational needs. Therefore, specific mechanisms and service architectures for the provision of citizens' access to health information are needed.

Personal health information is currently exchanged between healthcare providers and patients in different ways. A typical solution is to offer a provider-specific web service, such as the PAMFOnline service, for the citizen [2]. This approach is reasonable for citizens needing frequent interaction with the same healthcare provider. An alternative approach combining information from various sources into "health-record banks" has been proposed in [5]. Electronic mail, as a generic communication channel, provides a largely accessible and convenient way to access different providers [3]. However, transmission of personal health information by basic e-mail is not secure and in clear contradiction with the HIPAA (Health Insurance Portability and Accountability Act) legislation [4]. In order to provide secure and user-friendly information exchange, secure e-mail services have been established and their use in Business to Consumer (B2C) applications is steadily increasing [7].

The present paper introduces the PIR (Personal Information Repository) document service for communication between service providers and customers [9]. Being a generic, document-based solution PIR is similar to secure e-mail: it provides the customer a single interface for communicating with service providers. Additionally, the proposed service architecture enables health information to be exchanged in structured and standard form based on the HL7 Clinical Document Architecture Release 2 (HL7/CDA R2) [6]. This approach enables health information to be accessed and used by other applications. For example, health data originating from different sources over time can be displayed in graphical form. Besides health services, any other services involving personal information exchange may be included in the service portfolio. For example, communication between personal trainer service and the wellness customer can be provided and the related information can be viewed together with clinical data.

The PIR Document Service is described in more detail in Section II. The service has been tested in a user trial involving both healthcare professionals and citizens. Section III describes the test cases of the user trial and Section IV presents the results. Discussion and conclusions are given in Section V.

\section{SERVICE ARCHITECTURE}

Document-based service architecture has been adopted for the PIR service. This approach facilitates legally valid transactions since the documents can be digitally signed. The documentbased approach has a clear analogy with conventional letter mail, which simplifies the integration of the document service in legacy healthcare processes.

The overall PIR Document Service architecture is shown in Figure 1. The Document Server is the central component of the document service. It mediates documents between healthcare service providers and their customers. XMLmessages carried on https protocol are used to establish the customer and service provider subscriptions and to control the communication of information contents. The information

Permission to make digital or hard copies of all or part of this work for personal or classroom use is granted without fee provided that copies are not made or distributed for profit or commercial advantage and that copies bear this notice and the full citation on the first page. To copy otherwise, to republish, to post on servers or to redistribute to lists, requires prior specific permission and/or a fee. PERVASIVEHEALTH 2008, 30 Jan - 1 Feb. Tampere, Finland / Copyright $\odot 2008$ ICST 978-963-9799-15-8 DOI 10.4108/ICST.PERVASIVEHEALTH2008.2502 
contents can be either structured (e.g. HL7/CDA R2) or unstructured (e.g. pdf, jpeg, ...) documents.

The Document Server maintains lists of subscribed health service providers and their customers. It also provides the storage space and the necessary interfaces for establishing and maintaining document exchange connections. The mediator services can be outsourced to a third party since critical document content is end-to-end encrypted and, consequently, the mediator service provider does not have access to it.

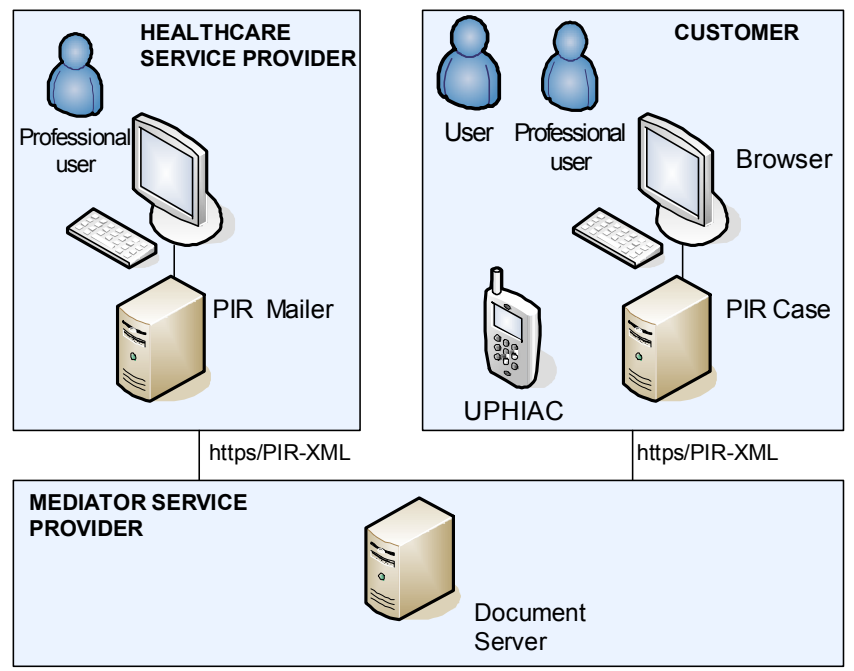

Figure 1. PIR Document Service architecture.

The customer may use either a browser or installed software (PIR Case) for accessing the Document Server. The browser interface provides basic functionalities for sending, receiving and managing documents while PIR Case provides additional functionalities such as support for local document management and content encryption. PIR Case uses an open protocol (PIR-XML) for communication. Both user interfaces support filling and submitting forms based on the W3C XForms recommendation. In addition, a mobile terminal application, UPHIAC [8], is available for uploading information from measurement devices to the server. The Document Server informs the customer about incoming documents via e-mail or sms-messages. External service is used for authenticating the user for the PIR Document Service.

\section{USER TRIAL}

The objective of the trial was to collect initial information about user acceptance and requirements in selected use cases. The trial, carried out in April-August 2006, included exchange of clinical information as well as personal wellness information. Clinical information use cases in Jorvi Hospital, Espoo, included delivery of laboratory results, collecting patient information on forms and posting of the epicrisis after hospital visit. Seventeen patients and 4 personnel members participated in these use cases. The use case in North Karelia Central Hospital, Joensuu, included messaging between patient and doctor. Five patients and one doctor participated this use case. The use case of private health clinic involved integration of the document service with patient information system. The objective was to demonstrate the possibility to send information to the patient directly from the patient information system (Doctorex). One patient and two doctors participated this use case.

The Personal trainer service use case involved a group of eight healthy persons receiving feedback from personal trainer while carrying out a physical exercise programme. The customers in this use case had personal wrist computers (Suunto T6) for registering exercise data such as the heart beat rate and excess post-exercise oxygen consumption (EPOC). The exercise data was shared with the personal trainer by using the PIR Document Service.

One business-to-business (B2B) use case was included in the trial. It involved sending of referrals concerning diabetes instrument delivery between the Jorvi hospital and four primary care units in the city of Espoo. The primary care personnel (4 persons) were regarded as customers in the trial, since they used the customer's user interface to access the document service.

Additionally a group of "other test persons" was involved. This group of 5 healthy subjects were trying out the document service for messaging. Altogether, the trial was participated by 42 customers and 13 personnel members. An inquiry form was filled in after the participation to the trial. All personnel members replied the inquiry while the percentage of replies from customers was $48 \%$.

\section{TRIAL RESULTS}

Service usability was evaluated separately for the start-up phase and for actual use. The start-up phase involved installation of the software (PIR Case users) and subscribing to the service point relevant to the use case. Based on a given information leaflet, the customers had to first locate the web address for installing the software or using the service with a browser. They also had to use their authentication or pin code (given in the leaflet) or their existing bank password list for subscribing to the health service. For the personnel, the startup phase was easier, since the required software (PIR Mailer) was installed and initialized by the IT support. The results for service usability in the start-up phase are shown in Figure 2.

A major part (79\%) of the customers using the browser found the service start-up phase easy or fairly easy. The corresponding proportion for PIR Case users was $76 \%$. Taking into account, that PIR Case software had to be separately installed, the difference is small.

PIR Mailer software was considered as easy or fairly easy by $60 \%$ of the personnel respondents. According to the feedback, it seems clear that the personnel expect the new functionalities to be integrated with the patient information systems. This is supported by the fact that the start-up phase was considered easy by the two doctors using the patient information system as the user interface instead of PIR Mailer software. 


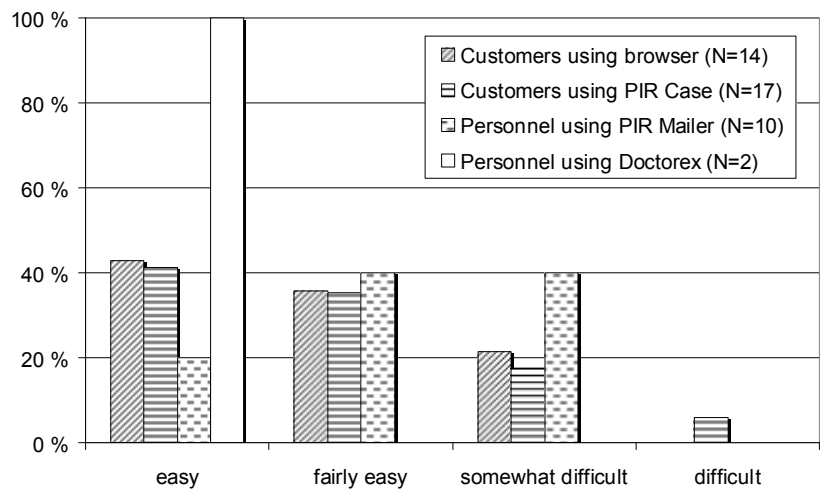

Figure 2. Customer and personnel experience from the start-up phase.

Authentication is carried out by the customer as one important part of the start-up phase. Bank password lists are largely used for authentication in internet services in Finland. Mobile phone based authentication is an emerging technology. In the mobile authentication procedure, a pre-assigned pin code was requested to be entered by the user as a response to an automatic call during the service subscription phase. As shown in Figure 3, nearly all respondents considered the authentication procedure easy or fairly easy. The bank passwords were considered most easy, likely because of their familiarity from network banking usage.

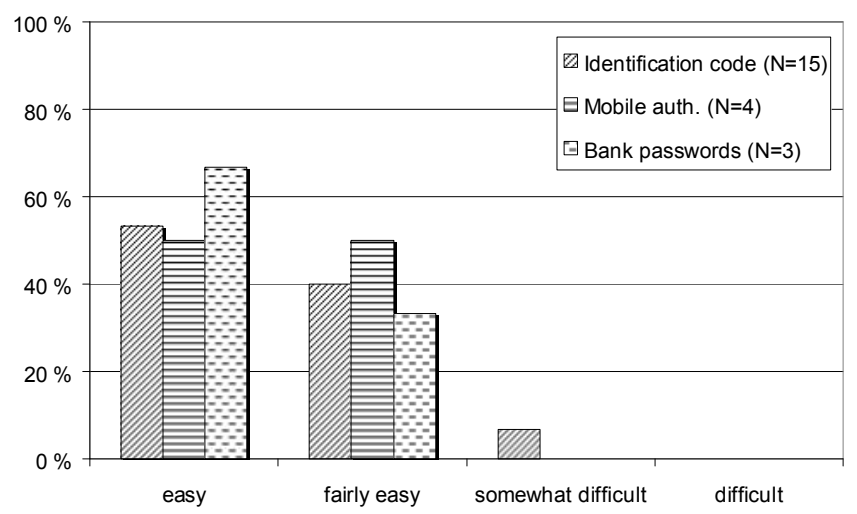

Figure 3. Customer authentication experience.

The experiences from actual use of the document service are shown in Figure 4. Concerning the customers, PIR Case was considered more user-friendly than the browser interface. It was experienced easy or fairly easy by $83 \%$ while the corresponding proportion for the browser users was $58 \%$. This result was expected, since the responsiveness of the locally installed software is better and it offers a richer user-interface. As in the start-up phase the personnel liked most the usage through the Doctorex software. Using the separate application (PIR Mailer) was considered easy or fairly easy by $70 \%$ of the respondents. The experience of service usefulness is shown in Figure 5 and Figure 6 . From all customers $70 \%$ considered the service useful or fairly useful. The opinions varied somewhat in the use cases: the two test persons were most positive while only $62 \%$ of the exercise group considered the service fairly useful.

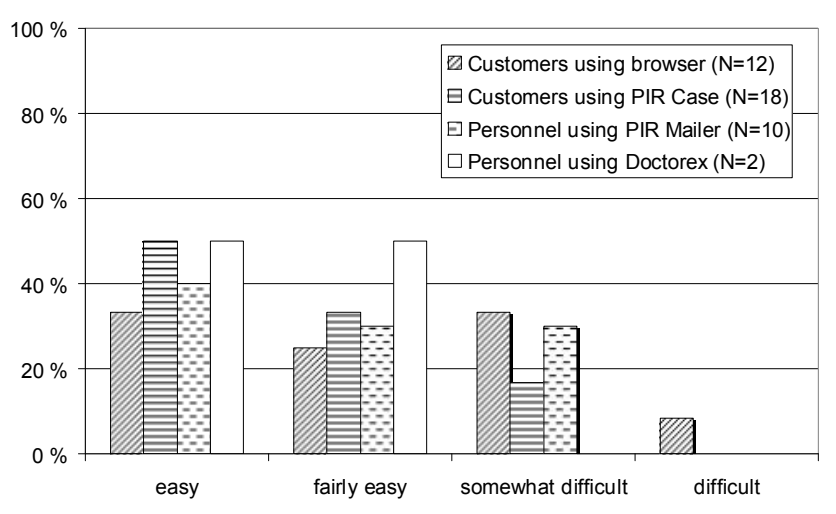

Figure 4. Customer and personnel experiences from actual use.

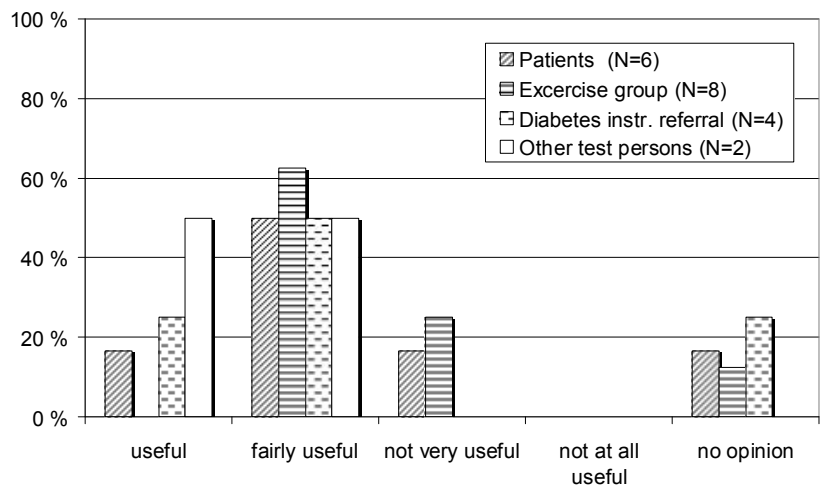

Figure 5. Usefulness of the service experienced by the customer.

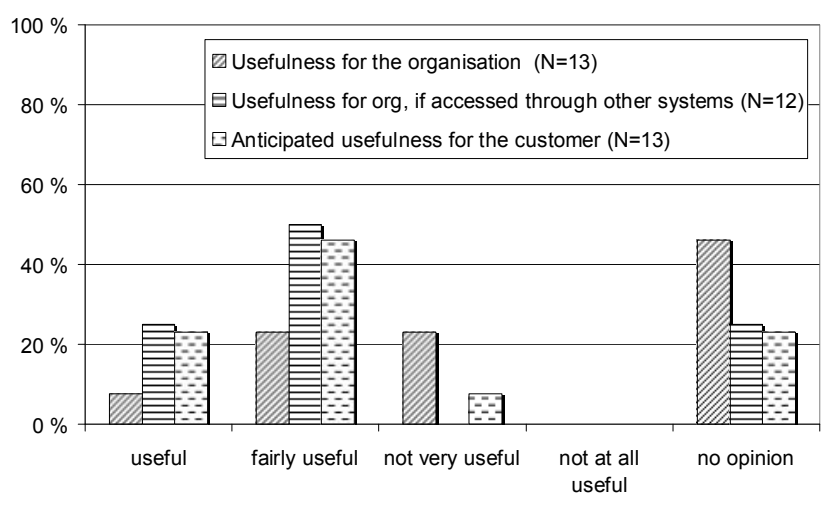

Figure 6. Usefulness of the service experienced by the personnel.

The personnel were positive about usefulness provided that the service can be accessed through existing patient information systems. In this case $75 \%$ of the respondents considered the service as useful or fairly useful for their organization. Assuming that a separate application would be needed, the corresponding proportion was only $31 \%$. From the personnel, $69 \%$ anticipated the service to be useful or fairly useful for the customer.

Technical problems were mostly experienced by the exercise group. The exercise group members had to use a separate 
program for retrieving the exercise data from the wrist computers and the required procedure for moving information into the PIR Document Service was complicated according to the received feedback. $75 \%$ of the customers in the other use cases experienced no problems or only minor problems. The corresponding proportion for the personnel was 54\%. The customers' willingness to use a similar operational service was quite high assuming that the service is free of charge. The patients were most positive: all of them would use the service certainly or probably. The exercise group was somewhat less interested, which is in line with the results concerning usefulness of the service Figure 5. Considerable amount (more than $60 \%$ ) of the respondents of the exercise group and the patients did not rule out a service with price.

\section{DISCUSSION AND CONCLUSIONS}

The introduced service architecture differs from many existing approaches since it is document-based and shared among several health service providers. The immediate advantages of this approach are expected to occur for the customer, since the same user interface is used to access the content originating from different providers. Though, validation of the expected benefits in user trial is challenging. For the benefits to be clearly visible, an extensive user trial would be needed. More providers should be involved to see the advantage of a shared architecture, while the customer's needs for a variety of services would occur only during a longer trial period. Due to the small number of participating users it is not possible to draw any definitive conclusions based on the user trial carried out. However, a number of interesting issues concerning user experience and requirements have been revealed. These provide a good basis for further development of the documentbased service and more extensive user trials.

Concerning the customer experience, the need for easy and intuitive user interface was apparent: many customers (e.g. $50 \%$ of the patients) did not use the user manual at all. Some problems were caused by the fact that the customer had to find and subscribe to the correct service provider before any communication could take place. This is the downside of the approach, which offers single user interface for several services. However, the customers seemed to appreciate the multi-service approach: $85 \%$ of the respondents considered the service useful or fairly useful provided that several services can be accessed.

The challenges of applications involving additional measurement devices are obvious. The measurement devices should be seamlessly integrated to the document service without the need for manual operations. In order to achieve high usability locally installed software has to be used instead of a browser. For the user convenience it is important that the software to be installed is small in size enabling quick installation and removal.
One of the barriers in providing electronic services for healthcare has been the lack of viable business models. The trial results are in line with those reported in [2] suggesting that a reasonable fee could be charged for the electronic service. Charging could take place in connection with the payment for the treatment.

From the healthcare personnel point of view the message was clear. The user interface for communicating with the customers should be embedded in the other patient information systems being used in the organization. From the feedback it is also apparent that the customer service process has to be well defined and integrated with the patient care process. This is important in order to realize the efficiency improvements in practice. The challenge comes from the fact that only a certain part of the patients have the possibility and are willing to communicate electronically with the health service providers. Therefore, holistic solutions incorporating electronic channels and conventional access methods, such as paper letters, should be developed.

\section{ACKNOWLEDGMENT}

The authors would like to thank all the personnel contributing to the user trial, in particular Mr. Jari Simonen and Mr. Juha Syrjäläinen from the Hospital District of Helsinki and Uusimaa and Mr. Esa Korkeela from the North Karelia Hospital District.

\section{REFERENCES}

[1] Y. Sumita, M. Takata, K. Ishitsuka, Y. Tominaga and K. Ohe, " Building a reference functional model for EHR systems," Int. J. of Medical Infromatics, Vol. 76, No. 9, Sept. 2007, pp. 688-700.

[2] K. Ilvonen, N. Ekroos, J. Kujala, "Internet and browser based system effects on preliminary care process", TKK/HEMA report 2006, 60 p. Available: http://www.bit.hut.fi/hema/

[3] C. B. White, C. A. Moyer, D. T. Stern, Steven J. Katz, "A Content Analysis of E-mail Communication between Patients and Their Providers: Patients Get the Message," Journal of American Medical Informatics Association. 2004;11:260-267. DOI 10.1197/jamia.M1445.

[4] J. Hash, P. Bowen, A. Johnson, C. D. Smith, D. I. Steinberg, "An introductory resource guide for implementing the Health Insurance Portability and Accountability Act (HIPAA) Security Rule," NIST Special Publication 800-66, March 2005, 129 p.

[5] J.D. Gold and M.J. Ball, "The Health Record Banking Imperative: A Conceptual Model," IBM Systems Journal, 46(1): 2007, pp. 43-55.

[6] R. H. Dolin, L. Alschuler, S. Boyer, C. Beebe, F. M. Behlen, P. V. Biron, A. Shabo, "HL7 Clinical Document Architecture, Release 2," Journal of the American Medical Informatics Association, Vol. 13, No. 1, Jan/Feb 2006, p. 30-39.

[7] MarketScope for E-Mail Encryption, 2006, Gartner, 21 April 2006/ID Number: G00138548.

[8] T. Laakko, J. Leppänen, J. Lähteenmäki, A. Nummiaho," Multipurpose mobile platform for telemedicine applications," accepted for publication: Pervasive Health 2008, January 2008, Tampere, Finland.

[9] PIR Document service web page: $\underline{\text { www.pir.fi }}$ 